\title{
A Security System for Kindergarten School Using RFID Technology
}

\author{
Salma Nazia Rahman'1, Shikder Shafiul Bashar1*, Md. Abdullah Al Mahmud1, Md. Sazal Miah', \\ A. H. M. Zadidul Karim¹, Maliha Marium² \\ ${ }^{1}$ Department of Electrical and Electronic Engineering, University of Asia Pacific, Dhaka, Bangladesh \\ ${ }^{2}$ Department of Computer Science and Engineering, University of Asia Pacific, Dhaka, Bangladesh \\ Email: salma@uap-bd.edu, bashar96.uap@gmail.com, abdullah-eee@uap-bd.edu, sazalmiah94@gmail.com, zadid@uap-bd.edu, \\ marium4102@gmail.com
}

How to cite this paper: Rahman, S.N., Bashar, S.S., Al Mahmud, M.A., Miah, M.S., Karim, A.H.M.Z. and Marium, M. (2019) A Security System for Kindergarten School Using RFID Technology. Journal of Computer and Communications, 7, 21-30. https://doi.org/10.4236/jcc.2019.74003

Received: February 23, 2019

Accepted: April 13, 2019

Published: April 16, 2019

Copyright $\odot 2019$ by author(s) and Scientific Research Publishing Inc. This work is licensed under the Creative Commons Attribution International License (CC BY 4.0).

http://creativecommons.org/licenses/by/4.0/

(c) (i) Open Access

\begin{abstract}
An RFID (Radio Frequency Identification) based security and access control system is proposed in this paper. Recently, a crime against children is increasing in higher rate and it is high time to offer a safety system for the school going children. In this work, our aim is to build a security system to keep the student secure. This system provides a unique identification number that is RFID card. Generally, the RFID card will be scanned in an RFID reader. RFID reader will send data to Arduino where the database program is previously set. Arduino programs are written in C language. If anyone remains absent after school starts, the GSM module will send an automated SMS to his or her parents. Students may need to leave school for an emergency case. Then he/she can take special permission from the administration. There is a button set for the administration to open the gate immediately for this reason. Parents will be provided RFID card from the school authority. Because student card won't work for the second time in a day. So parents will have to scan their card after school to receive their children. And their card will only work after school. Hence, the risks of any occurrence are reduced and ensured the safety of the student.
\end{abstract}

\section{Keywords}

Radio Frequency Identification, Ardunio, Safety System, GSM

\section{Introduction}

Nowadays, security systems play a vital role in blocks unknown user entry into a secured area, which may contain both physical and intellectual property, without being recognized. There are various automatic identification technologies such 
as a barcode, magnetic stripe and Radio Frequency Identification (RFID) used in the security system. RFID is a rising technology and one of the most promptly growing segments of today's automatic recognition data collection. RFID technology offers admirable performance over other automatic recognition systems. The system shown in this paper uses an RFID tag which includes an integrated circuit that is used for accumulating, preparing unique information, modulating and demodulating the radio frequency signal being transmitted. A Global System for Mobile Communication (GSM) technology is to contact a security personnel via Short Message Service (SMS) in order to strengthen the safety. RFID based security system grants access to only recognized persons to a secured area [1].

Over the past few years, an innovative idea "Internet of Things (IoT)" which was first introduced by Kelvin Ashton in the year 1998, has gained huge attention in the academic and industrial sector. In recent years, scientists severely used the term "Internet of Things" to introduce to the general idea of things, especially the objects that are readable, recognizable, locatable, addressable, and controllable via the Internet-whether via RFID, wireless LAN, wide-area network, or other means. Radio frequency identification (RFID) is an automatic identification system which consists of readers and tags, which is said by John Wiley and Sons in 2003. Every RFID tag contains a unique identification number (ID) and a reader identifies an object through successive communications with the tag attached to it [2] [3] [4].

A wireless non-contact system is used by RFID. For transmission of data from a tag attached to an object, this type of system uses radio-frequency electromagnetic fields. The system designed in this project is implemented around an Ardunio which can help to avoid a human requirement in monitoring and keeping of record at the entrance of a secured area. This system establishes secured access control and record keeping.

Here, a security system is used for Kindergarten school where the gate will be opened automatically by using the correct RFID tag and count the attendance automatically. And if anyone is absent in the school, parents will be informed automatically through SMS by using GSM Module system. The system emphasized more of safety than the security of the school. RFID scanners scan the RFID card and pass the correct one. Then, the Servo motor opens the gate automatically by programming. If any student is late, then he can get access to the campus within a certain period of time by showing exact cause of being late by getting special permission from the administration. But if any student comes after that time or remains absent that day, then their parents will be informed by an automated SMS with GSM module system. If anyone wants to go home before school time ends, then he/she should have to show proper reason so that the administration can help him/her and inform his/her parents. And after school time, the gate will be opened automatically [5]. The simple block diagram of this project is shown in Figure 1. 


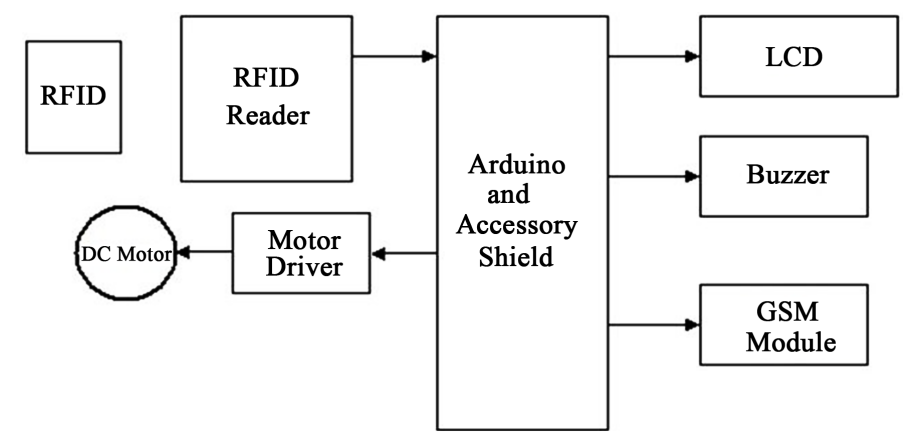

Figure 1. Simple block diagram of RFID based security system.

\section{RFID Based Security System}

In present days, because of the higher rate of kidnapping parents are worried about their children. Moreover, parents are having long working hours, so they simply do not have as much time to spend on their children. Recently in our country Police found the body of a missing school student in Kashimpur area of Gazipur. His name was Saidur Rahman and he was 13 years old, went missing on September 8, 2017. He was a student of local Dhanshiri School [6]. It is also occurring internationally. A 10-year-old boy who went missing after his mother dropped him off at school Monday morning at École Viscount Alexander, Canada [7]. Here RFID (Radio-frequency identification) based security system has been used for Kindergarten school. Because RFID is an automatic identification system. Like a barcode or the magnetic strip on a credit card, an RFID tag provides a unique identification code that can be read by a scanning device. Radio waves used in RFID to communicate with readers. After these waves reader converts them into digital data that identifies the object that contains the tag (Figure 2).

This paper shows an RFID based Kindergarten school security system using Arduino UNO R3, Grove $125 \mathrm{kHz}$ RFID reader, RFID tag, Arduino GPRS shield, Accessory Shield, Servomotor etc.

\section{System Design}

This Whole project based on RFID technology. So it consists of two part. One is hardware and another is software. In the hardware part, many components are used such as RFID reader and tag, Arduino UNO, GSM Module etc. In the software part, a program based on the $\mathrm{C}$ language is used. Here the block diagram of our project is described in Figure 3.

This project aims at providing a secure authentication system based on RFID tags that allow the only student with authorized RFID tags to access school premises. The tag contains an integrated circuit that is used to store, process the data and then modulate and demodulate the RF signals which are being transmitted. So as soon as a student brings the RFID card before the reader, the card is scanned and card data is compared with registered student's data. Here LCD display is used to show "Name of Student, ID Number, Class Level, and section" 


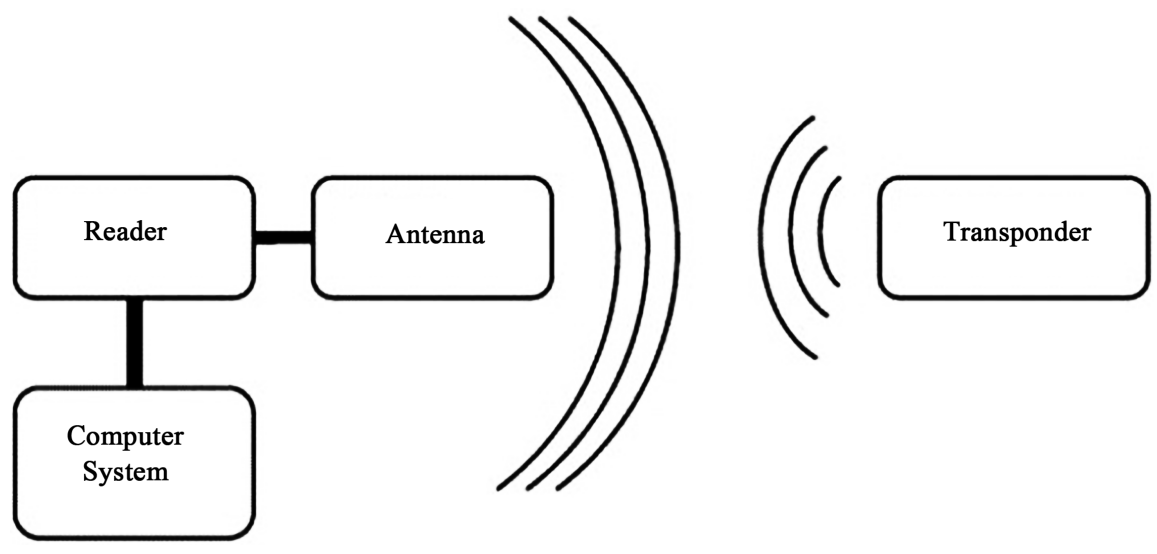

Figure 2. Basic RFID system.

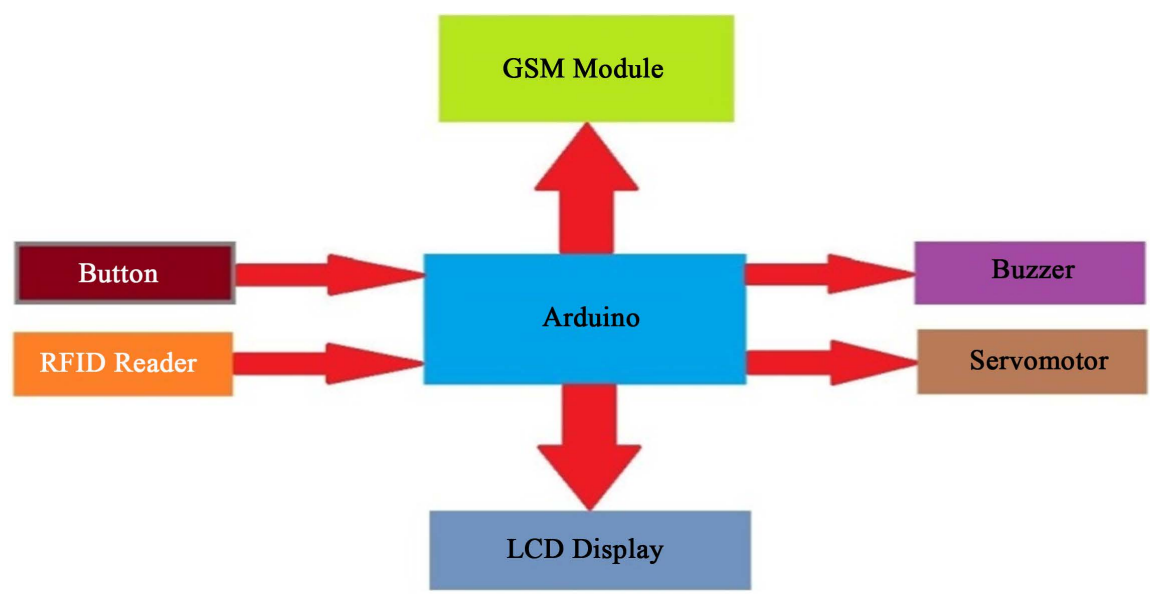

Figure 3. Block diagram of the proposed RFID based security system.

if the tag matches else it will show "You Are Not A Registered Student". It counts automated attendance of students and saves it on memory. If any student remains absent till half an hour after school starts automated SMS will be sent to his/her guardian. And the students RFID card will work only once in a day. If any student gets sick or wants to go home for some important reason then he/she will have to get special permission from the Principle of the school. That's why a special button is kept to open the gate immediately. If the administration grants the student to leave the school then the button will have to press to open the gate for the student. Parents can access the school premises after the school ends to receive their children by scanning their own RFID card (Figure 4).

1) Hardware Design

The hardware of the system mainly comprises RFID Tag, RFID Reader, Arduino UNO, LCD Display, Buzzer, Servomotor, GSM Module, Tactile Button and power supply.

2) RFID Tag

An RFID tag is an electronic tag that transfers data with an RFID reader over radio waves. Maximum RFID tags are consists of at least two main parts. First one is an antenna, which used to receive radio frequency (RF) waves. And the 


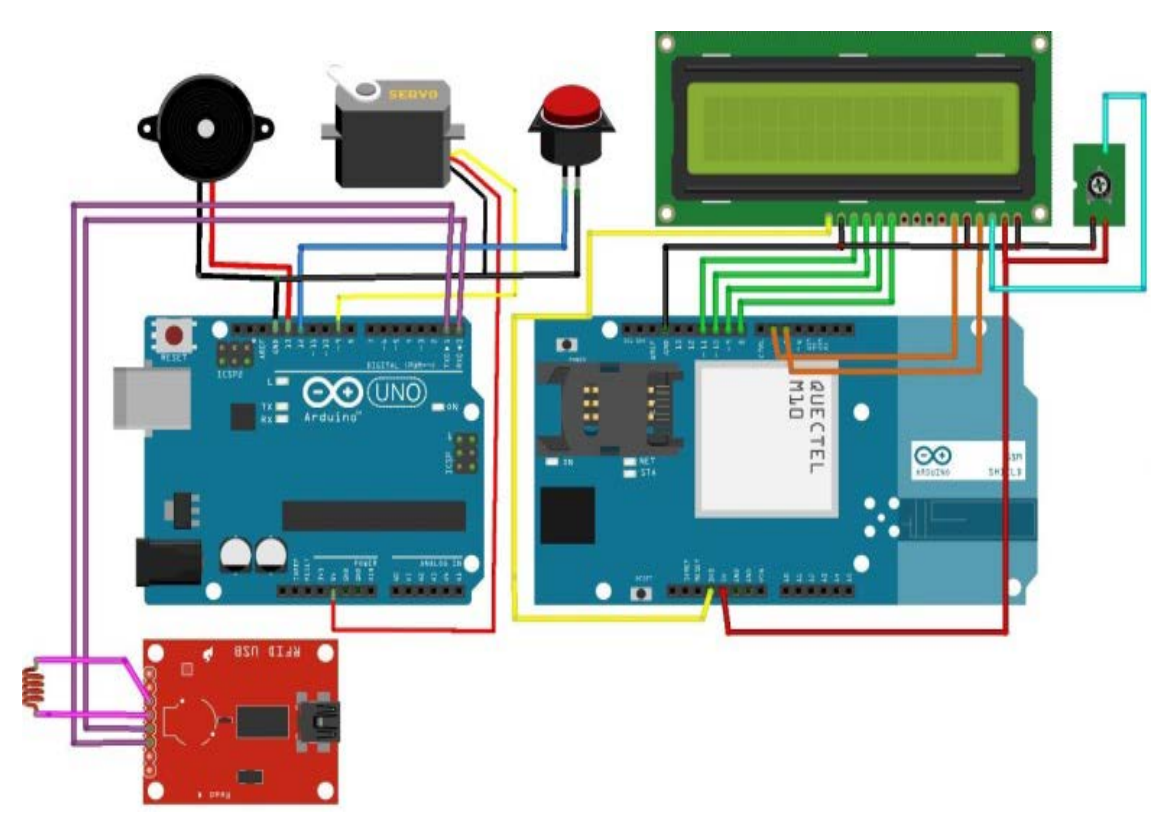

Figure 4. Circuit diagram of RFID based security system.

second part is an integrated circuit (IC), which is usually used for processing and accumulating data, along with modulating and demodulating the radio waves transmitted or received by the antenna. An RFID tag is also familiar as an RFID chip.

Two types of RFID Reader are available, Such as Active and Passive. Active RFID systems are battery-powered. These types of systems continuously transmit their own signal. Active RFID tags can precisely trace the real-time location of assets. Active tags maintain a longer reading capability than passive tags, but they are too expensive. No internal power source is required in the passive RFID system as they are powered by electromagnetic energy transfer from an RFID reader. The passive RFID systems economical for many industries due to lower price point per tag. RFID card is distributed by school authority among every students and parent. Identification number of every RFID tag is unique. For the entrance in the school, every student must carry this card for scanning (Table 1).

3) RFID Reader

The RFID reader used to compile data from an RFID tag to trace individual objects. Transmission of data from the tag to a reader is done by using radio wave. The direct scan is not needed for RFID tag. For successful reading, RFID tag must be within the ranges from 3 to 300 feet of an RFID reader. Fast identification of a specific product is enabled by RFID technology, even when it is surrounded by other items (Figure 5 ).

When student scans their RFID card to the scanner, the scanner reads the tag number. It passes authorize people and blocks unauthorized people. The reader reads the students RFID card once a day before school starts. After school starts student card won't work anymore.

4) Arduino UNO 


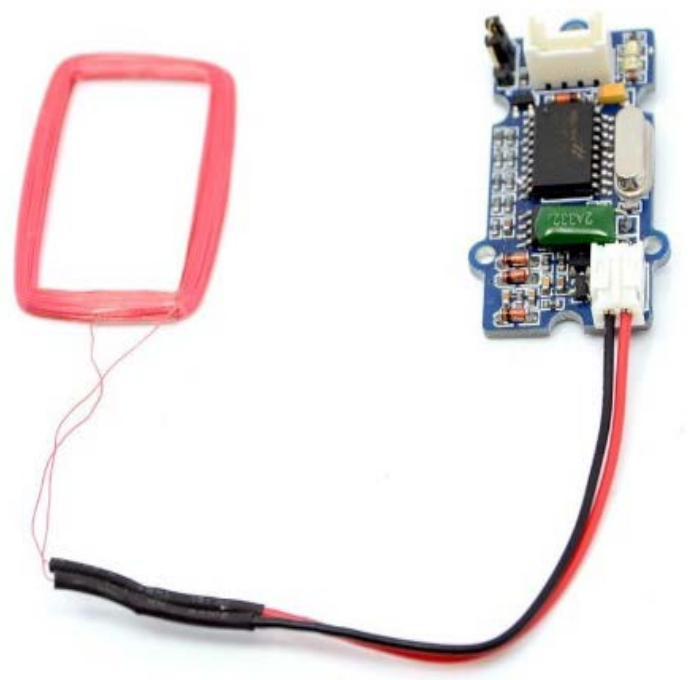

Figure 5. Grove-125 KHz RFID reader.

Table 1. Comparison of active and passive RFID tags.

\begin{tabular}{ccc}
\hline Attribute & Active Tags & Passive Tags \\
\hline Power Sources & Built-in Battery & Electromagnetic Induction \\
Reading Capability & Higher $(22$ to $102 \mathrm{~m})$ & Lower $(\mathrm{Up}$ to $2.5 \mathrm{~m})$ \\
Required Signal Strength & Lower & Higher \\
Tag Cost & Higher $(\$ 14$ to $\$ 100)$ & Lower $(\$ 0.15$ to $\$ 5)$ \\
Data Storage & Large read/write data $(128 \mathrm{~kb})$ & Small read $/$ write $(128 \mathrm{~kb})$ \\
Size & Larger & Smaller \\
Weight & Larger & Smaller \\
Tag Life & $\begin{array}{l}\text { Smaller }(3 \text { to } 8 \text { years } \\
\text { depending upon tag } \\
\text { transmission rate })\end{array}$ & $\begin{array}{c}\text { Larger }(\text { Up to } 10 \text { years } \\
\text { depending upon the } \\
\text { environment the tag is in) }\end{array}$ \\
Tag Readers & Cheap & Expensive \\
\hline
\end{tabular}

The ATmega328P is used in microcontroller board of Arduino Uno. This board contains 14 digital input/output pins, 6 analog inputs, a USB connection, a power jack, a $16 \mathrm{MHz}$ quartz crystal, an ICSP header, and a reset button. To use this device we connect it to a computer with a USB cable or power it with an AC-to-DC adapter or battery [8].

"Uno" means one in Italian. Uno was chosen to name the release of Arduino Software (IDE) 1.0. The first board in a series of USB Arduino and the reference model for the Arduino platform boards is the Uno board (Figure 6).

5) GSM Module

The international standard for mobile telephones is GSM. GSM stands for Global System for Mobile Communications. As it is a second-generation cellular network, it also referred to as 2G. For internet access purpose GPRS is used, and for the Arduino to request or serve web pages (Figure 7). 


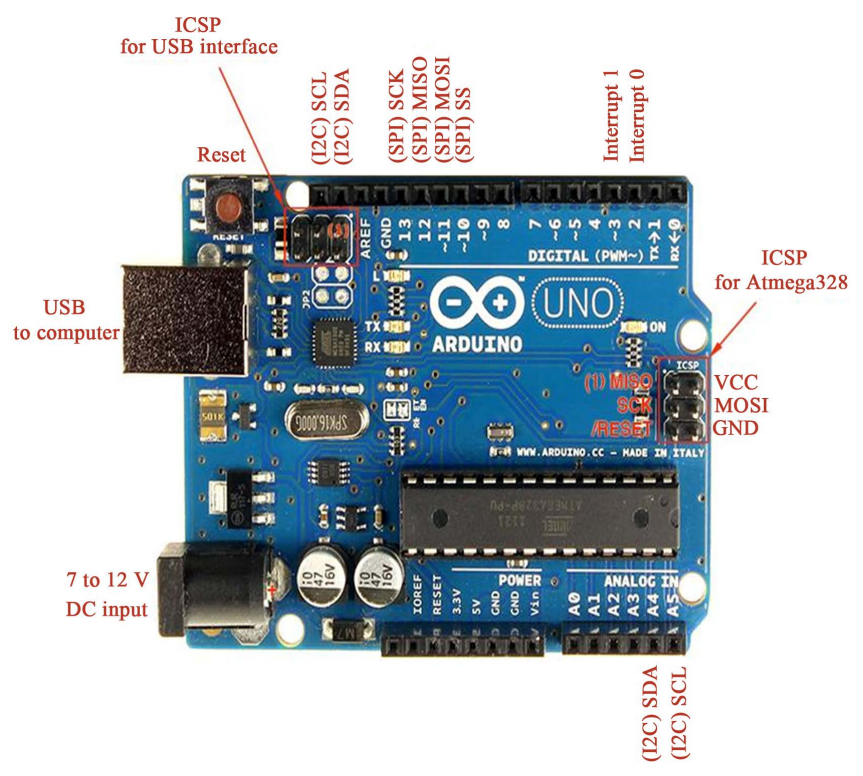

Figure 6. Arduino UNO's PIN configuration.

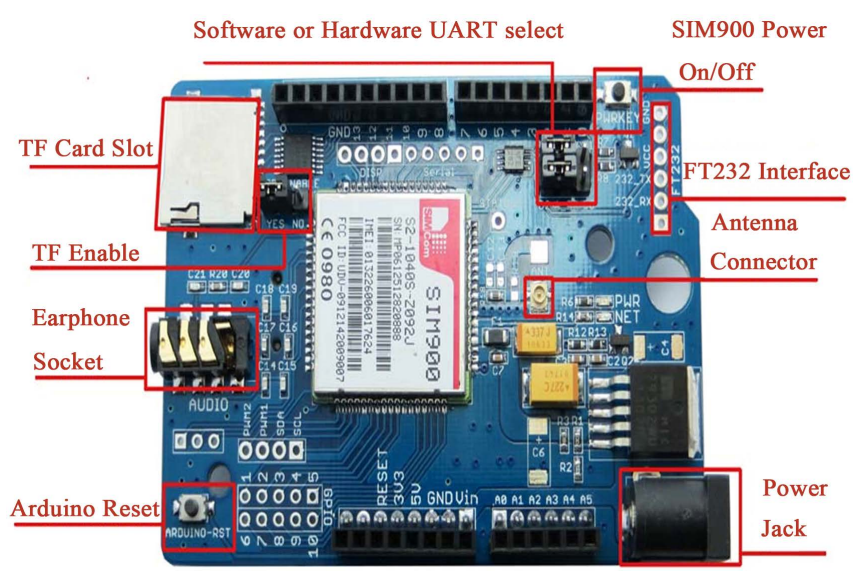

Figure 7. Arduino GPRS Shield's PIN configuration.

Outgoing and incoming voice calls, Simple Message System, and data communication via GPRS are also supported by GSM. The Arduino GSM shield is a simple GSM modem. The Arduino GSM shield seems just like a mobile phone, in term of mobile operator perspective. But the Arduino GSM shield looks just like a simple modem, in term of the Arduino perspective. It mainly creates a network with any operative SIM. Whenever student stays absent in the school an automated message has been sent to the parents.

6) Software Design

Here the program for our project is loaded previously in the Arduino. C language is used as our program language.

\section{Implementation of the Proposed Project}

The implementation of Security system has been implemented in Arduino Uno. The complete hardware unit of the system is shown in Figure 8 \& Figure 9. This 


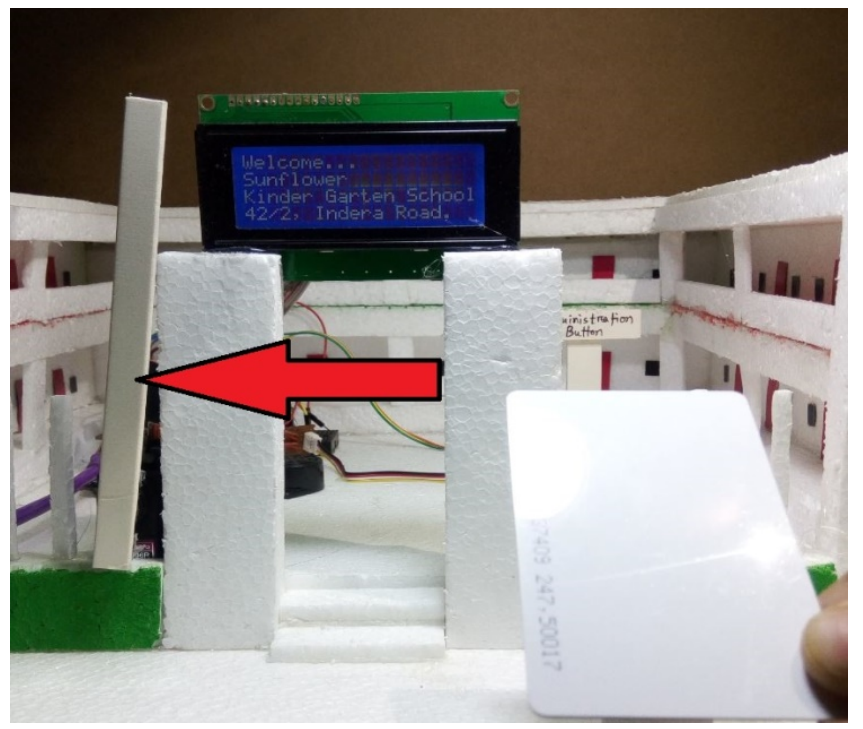

Figure 8. Front view of the hardware unit of our proposed security system.

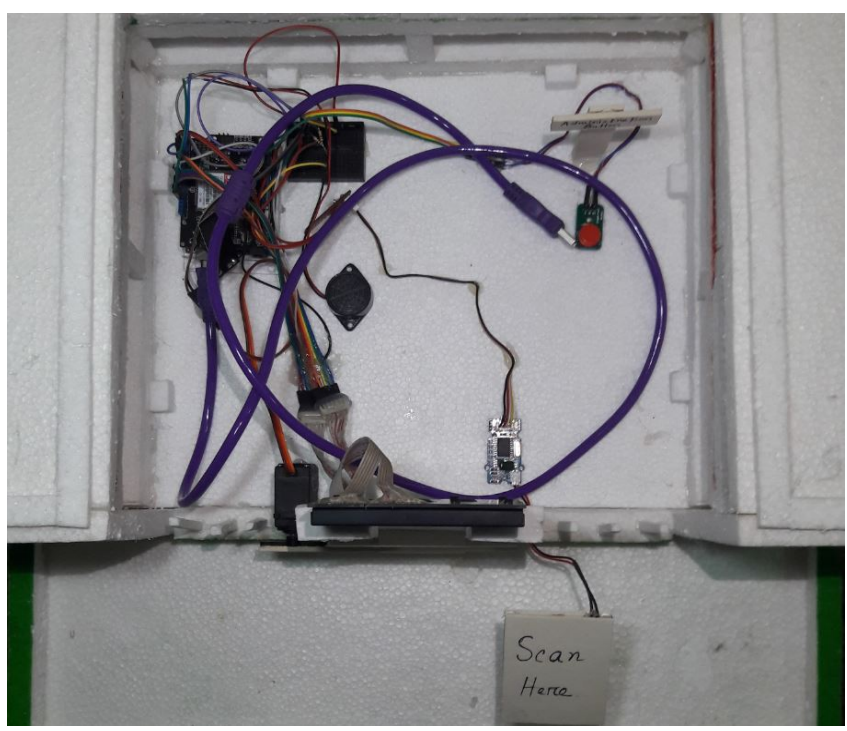

Figure 9. Top view of the hardware unit of our proposed security system.

system allows RFID card of any student once a day. The student can be late for some reason so we have given an extra time for their benefit. But if they cannot reach within the given time the student RFID card won't work any longer. Then an automated SMS will be sent to their parents that "Your Child is Absent Today". There is a functional button set for the administration for the special purpose to open the gate at any time. When school ends guardian can access into the school to receive their child by scanning their RFID card. In order to produce useful output, hardware \& software must work together. Nothing useful can be done with the hardware on its own \& software can't be utilized without supporting hardware. So, there is a close connection between software \& hardware. From the above discussion, it is realized that the whole project depends on the combination of two sections. Here software section is most important. Be- 
cause the hardware section can be used in different purposes by changing the command in the program.

\section{Conclusion \& Future Work}

This whole project is designed for the safety of the school going students. The system is more secure than any past security system. The authority of the school provides a unique identification number among every student. They can enter the school by scanning their own card and the data will be recorded in the administration. If anyone remains absent, an automated SMS will be sent by the database system to his or her guardian. The administrator has the power to open the gate by pressing a special button which is set previously in the administration. Parents will have to get their child after the school by pressing their RFID card which is provided before.

This project can be modified and also some new features can be added. If anyone wants to modify this project in future, then he can just use the GPRS function of GSM module to store data in the cloud database. It can be made more secure by adding a CCTV camera on it. If anyone wants to avoid RFID technology, then he can use a fingerprint scanner or face recognition. This project is not only for school security, but can be also used in different commercial space.

\section{Conflicts of Interest}

The authors declare no conflicts of interest regarding the publication of this paper.

\section{References}

[1] Zhu, X.W., Mukhopadhyay, S.K. and Kurata, H. (2012) A Review of RFID Technology and Its Managerial Applications in Different Industries. Journal of Engineering and Technology Management, 29, 152-167.

https://doi.org/10.1016/j.jengtecman.2011.09.011

[2] Fang, Z.Y., Wei, L., Chen, W. and He, Y.J. (2012) A RFID-Based Kindergarten Intelligence Security System. In 2012 IEEE Ninth International Conference on e-Business Engineering, Hangzhou, 9-11 September 2012, 321-326. https://doi.org/10.1109/ICEBE.2012.59

[3] Vidyasagar, K., Balaji, G. and Narendra Reddy, K. (2015) RFID-GSM Imparted School Children Security System. Communications on Applied Electronics (CAE), 2, 17-21.

[4] Curran, K. and Norrby, S. (2009) RFID-Enabled Location Determination within Indoor Environments. International Journal of Ambient Computing and Intelligence (IJACI), 1, 63-86. https://doi.org/10.4018/jaci.2009062205

[5] Iyer, S. (2005) RFID: Technology and Applications. Eleventh National Conference on Communications.

https://www.worldcat.org/title/proceedings-of-the-eleventh-national-conference-on -communications-ncc-2005-28-30-january-2005/oclc/296289117

[6] http://www.dhakatribune.com/bangladesh/nation/2017/10/04/police-found-body-of -missing-gazipur-school-boy/ 
S. N. Rahman et al.

[7] http://www.cbc.ca/news/canada/manitoba/missing-boy-dropped-off-at-school

[8] http://www.raviyp.com/embedded/158-difference-between-arduino-and-microcont $\underline{\text { roller }}$ 